\title{
ПРИЧИНЫ КОНСТИТУЦИОННЫХ КОНФЛИКТОВ В РОССИЙСКОЙ ФЕДЕРАЦИИ В КОНТЕКСТЕ ТЕОРИИ КОНСТИТУЦИОННОЙ ЭКОНОМИКИ: ПОВЕДЕНЧЕСКИЙ АСПЕКТ
}

\author{
И. А. Третьяк \\ Олский государственный университет илени Ф. М. Достоевского \\ Поступила в редакцию 10 июня 2021 г.
}

\begin{abstract}
Аннотация: статья посвящена определению причин поведения субъектов конституиионного права в условиях конституционных конблликтов. Автор разрешает с полощью эконолического анализа вопрос о природе, характеристиках такого поведения и условиях его фборлирования. В статье впервые приленены идеи конституиионной эконолики, теория общественного выбора для объяснения природы поведения участников конституиионного конобликта, а также приведены данные о результатах опроса граждан Российской Федерации о причинах конституиионных конфбликтов и способах их разрешения, которье подтверждают объективное существование конституиионньх конфбликтов и инфборлированность о них граждан.
\end{abstract}

Ключевые слова: конституиионная эконолика, поведение индивида, конституционный конфликт, рациональность, постконституционньии договор.

\begin{abstract}
: the article is devoted to determining the reasons for the behavior of subjects of constitutional law in the context of constitutional conflicts. The author resolves with the help of economic analysis questions about the nature, characteristics of such behavior and the conditions of its formation. This paper is the first application ideas of constitutional economics to explain the nature of the behavior of participants in a constitutional conflict. The article also provides results of a social research among citizens of the Russian Federation about the causes of constitutional conflicts and ways to resolve them, which confirm the objective existence of constitutional conflicts and the awareness of citizens about them.
\end{abstract}

Key words: constitutional economics, individual behavior, constitutional conflict, rationality, post-constitutional contract.

В конце прошлого столетия в юриспруденции получили активное развитие два междисциплинарных научных направления конституционная экономика (конституционная политическая экономия) ${ }^{1}$ и юридическая конфрликтология ${ }^{2}$.

${ }^{1}$ См., например: Конституционная әкономика / отв. ред. Г. А. Гаджиев. М., 2010 ; Конституционная экономика : учеб. для юрид. и экон. вузов / П. Д. Баренбойм [и др.]. М., 2006 ; Очерки конституционной экономики. 23 октября 2009 г. / под ред. Г. А. Гаджиева. М., 2009 ; и др.

${ }^{2}$ См., например: Кудрявиев $B . H$. Избранные труды по социальным наукам : в 3 т. М., 2002. Т. 2. С. 252 ; Его же. Юридическая конфликтология. М., 1995.

(C) Третьяк И. А., 2021 
Возможной причиной обращения юридического сообщества к экономике и социологии в части образования указанных междисциплинарных направлений явился обнаруженный юристами огромный объяснительный потенциал, который накопили данные науки о человеческом поведении, его мотивах и причинах, а также формах такого поведения в условиях существующих в обществе ограничений. Юриспруденция же могла объяснить вопросы формы, классификаций, признаков, в лучшем случае - сущности правового явления, но почему это явление именно такое, в чем причина его формирования - юристы далеко не всегда могли дать ответ.

В связи с этим Г. А. Гаджиев, один из ярких представителей отечественной школы конституционной экономики, выступая на Московском юридическом форуме, справедливо отметил, что к началу XX в. сложились традиционные юридические представления, согласно которым юриспруденция является сугубо автономной сферой научных знаний, независимой от других социальных наук дисциплиной; юристы были заняты классификациями, систематизациями, т. е. логической обработкой правовых норм с целью избегания противоречий ${ }^{3}$.

Вместе с тем некоторые ученые все-таки стремились к верификации юридического знания с помощью междисциплинарного подхода. В частности, Д. А. Керимов видел будущее отечественного правоведения в исследовании двух фундаментальных проблем - методологии права и в междисциплинарных исследованиях. Он писал о том, что наибольшего успеха достигают ученые, которые не пытаются с упорством узкого фанатизма сохранить превратно понятую «чистоту» своей дисциплины, ограждая ее от всяческого вторжения извне, но настойчиво и последовательно расширяют диапазон исследовательских усилий путем широкомасштабного и интенсивного привлечения инструментов и методов анализа, знаний и результатов, накопленных и используемых в других научных областях ${ }^{4}$.

Примером такого междисциплинарного подхода явилась работа коллектива авторов под руководством академика В. Н. Кудрявцева о юридической конфликтологии, увидевшая свет в 1995 г. ${ }^{5}$ В данной работе были сформулированы основополагающие идеи о существовании политических конфликтов, что стало толчком к изучению конституционных конфликтов как их разновидности.

С учетом данных идей об актуальности междисциплинарного знания автором настоящих строк длительное время изучаются конституционные

\footnotetext{
${ }^{3}$ См.: Гаджиев Г. А. Российские исследования в области права и экономики : уточнение юридической картины мира // Выступление на IV Моск. юрид. фроруме «Право и экономика : междисциплинарные подходы в науке и образовании» 6 апреля 2017 г. URL: http://www.ksrf.ru/ru/News/Documents/report_\%D0\%93\%D0 \%B0\%D0\%B4\%D0\%B6\%D0\%B8\%D0\%B5\%D0\%B2_2017.pdf. C. 2 (дата обращения: 13.05.2021).

${ }^{4}$ См.: Керилов Д. А. Методология права. М., 2009. С. 19.

${ }^{5}$ См.: Юридическая конфликтология / под ред. В. Н. Кудрявцева. М., 1995.
} 


\section{Вестник ВГУ. Серия: Право}

конфликты, результатом чего стало формирование теоретических основ конституционной конфликтологии как самостоятельного междисциплинарного раздела науки конституционного права ${ }^{6}$. Под конституционным конфликтом предлагается понимать противостояние и/или противодействие субъектов конституционного права по поводу конституционных ценностей, реализуемое в фрорме правоотношения и разрешаемое специальными конституционно-правовыми способами.

С точки зрения превентивной функции права особое значение приобретает своевременное выявление причин конституционных конфликтов. Наука конституционного права в качестве таковых предлагает рассматривать конкретные явления юридической действительности: коллизии и конкуренцию конституционных норм, пробелы в законе, неоднозначность толкования конституционных норм. При таком подходе существует риск рассмотрения конституционных конфликтов не как противостояние индивидов, а как «противостояние» конституционных норм. Данной точки зрения придерживаются отдельные исследователи. Например, А. А. Белкин писал о существовании текстуально-правовых конфликтов в Конституции РФ, которые он определял как некую группу юридических конфрликтов, которые выявляются при изучении (комментировании) правовых текстов, порядка их издания или в ходе правоприменения, выступают в виде конфрликтов именно самих отдельных правовых текстов или их совокупностей, а не конкретных субъектов права, даже если бы действия последних и способствовали обнаружению конфликтов, и преодолевались в рамках правоприменения, а не правотворчества. По мнению А. А. Белкина, текстуально-правовые конфликты охватывают следующие ситуации: некомпетентность правовых актов, коллизии норм, пробелы, субъектно-статусный дисбаланс, неопределенность содержания норм ${ }^{7}$.

При изучении данного явления, обнаруживаемого в нормах Конституции РФ, А. А. Белкин, стремясь выразить «правоприменительную неадекватность» как состояние нормативно-правовой системы, прибегнул к теории юридической конфликтологии, разработанной В. Н. Кудрявцевым. А. А. Белкин, бесспорно, был прав, отмечая, что «конфликктность» конституционно-правового текста содержит возможность реализации в конкретных социальных взаимодействиях и в правоприменении.

Вместе с тем В. Н. Кудрявцев сформулировал теорию юридической конфликтологии, основываясь на категории социального конфликта, под которым понимал процесс, в котором два (или более) индивида или группы активно ищут возможность помешать друг другу достичь определенной цели, предотвратить удовлетворение интересов соперника или изменить его взгляды и социальные позиции. При этом социальный конфрликт становится юридическим, если он протекает в сфере правовых отношений, порождается правовыми ситуациями, а затем и разрешается

${ }^{6}$ См.: Третьяк И. А. Конституционная конфликтология. М., 2021; Его же. Конституционно-конфрликтная диагностика. Омск, 2021.

${ }^{7}$ См.: Белкин А. А. Избранные работы 90-х годов по конституционному праву. СПб., 2003. С. 184-187. 
юридическими средствами ${ }^{8}$. В связи с частотой использования термина «конфликт» В. Н. Кудрявцев особо отмечал, что по аналогии данный термин может быть распространен на многое, вплоть до борьбы с неодушевленными предметами, но в социальном конфликте все стороны представлены людьми. Несмотря на то что проблематика конфликтов оперирует также такими терминами, как спор, соперничество, конкуренция, противоречия и т. д., В. Н. Кудрявцев, описывая подобные явления, всегда употреблял слово «конфрликт» в кавычках, поскольку такое его употребление было неадекватно представлению о конфликте как о социальном явлении ${ }^{9}$.

В продолжение рассмотрения юридического конфрликта как конфликта социального, суть которого есть определенное взаимодействие индивидов, отметим, что выдающийся социолог П. А. Сорокин еще в 1913 г. определял социальное явление как всякое взаимодействие, обладающее психическим характером ${ }^{10}$. Такое понимание сощиального явления, как взаимодействие индивидов, отчетливо сформировалось в начале прошлого века и было отражено в трудах Г. Зиммеля ${ }^{11}$ и Э. Дюркгейма ${ }^{12}$.

C учетом вышеизложенного мы придерживаемся социологического подхода к определению юридического, или правового, конфликта, который всегда есть явление социальной (реальной) действительности, в то время как «конфликт» норм вне правоотношения таким явлением социального бытия не является и отражен исключительно «на бумаге».

Следовательно, если конституционный конорлкт - это взаимодействие индивидов, то выбор ими варианта своего поведения также может определить причину конфрликта. Проиллюстрируем данный тезис следующим гипотетическим примером. Допустим, президенту стало известно о некоторых фрактах поведения губернатора $\mathrm{N}$, не соответствующих этике поведения лица, замещающего государственную должность. Несмотря на то что такие фракты формально не являются основанием для отрешения от должности губернатора в связи с утратой доверия президента в соответствии с фредеральным законодательством, у президента есть выбор следующих вариантов поведения: 1) отрешить от должности губернатора в связи с утратой доверия, несмотря на отсутствие юридического основания; 2) проигнорировать данные фракты и бездействовать; 3) применить меры организационного характера, не связанные с прекращением полномочий губернатора (например, провести совещание, на котором сделать устное замечание о недопустимости такого поведения лица, замещающего государственную должность, либо вынести предупреждение и т. п.). Возникает вопрос: почему президент выбирает определенный ва-

${ }^{8}$ См.: Кудрявцев B. Н. Избранные труды по социальным наукам. Т. 2. С. 250251.

${ }^{9}$ См.: Кудрявиев В. Н. Юридическая конфликтология. С. 252.

${ }^{10}$ См.: Сорокин П. А. Преступление и кара, подвиг и награда : социологический этюд об основных формах общественного поведения и морали. М., 2006. С. 90.

${ }^{11}$ См.: Зимлмель Г. Sociologie. Leipzig, 1908. P. 5-7.

${ }^{12}$ См.: Дюркгейли Э. О разделении общественного труда. Одесса, 1901. С. 221. 
риант поведения? Юридическая наука не дает на него ответа, поскольку в принципе выносит такой вопрос «за скобки» правовой материи и правового регулирования. Объяснение выбора варианта юридически значимого поведения только лишь реализацией усмотрения субъекта конституционного права также не привносит ни знаний, ни истины в решение вопроса о причинах выбора определенного варианта поведения.

Вместе с тем для всестороннего изучения конституционных конфликтов, тем более если оно осуществляется с позиций теории социологического конфликта, данный вопрос требует разрешения, иначе будет упущен существенный пласт поведенческого аспекта в конституционной конфликтологии.

В конституционных конфликтах участвуют субъекты, обладающие конституционной правосубъектностью, но, так или иначе, это всегда люди либо их общности в виде групп, организаций, органов публичной власти, многонационального народа Российской Федерации. Поэтому неизбежно возникают вопросы: почему люди поступают так, а не иначе? Почему или чем им «выгоден» такой вариант поведения, который приводит к возникновению конфликта как противостояния и/или противодействия? При таком подходе очевидно, что причина конфликта кроется не только в правоприменительной неадекватности нормы права, но и в реальном поведении участников социального взаимодействия. На этот счет весьма точно высказался Дуглас Норт, нобелевский лауреат по экономике, что «в явном или скрытом виде все теоретические исследования в области социальных наук опираются на некоторые концепции человеческого поведения» ${ }^{13}$. Полагаем, что юриспруденция как гуманитарная наука должна также прибегнуть к таким концепциям, чтобы объяснить поведение индивидов в условиях конституционных конфликтов.

В связи с этим ответы на поставленные выше вопросы были нами обнаружены в работах Джеймса Бьюкенена, лауреата нобелевской пре일 мии по экономике за исследование конституционных основ в принятии - экономических и политических решений, основоположника теории кон尺े ституционной экономики (конституционной политической экономии), a также в научных трудах представителей российской школы конституционной экономики (Г. А. Гаджиева, П. Д. Баренбойма, В. И. Лафотского, 24 В. А. Мау и др.).

По поводу конституционной экономики А. И. Казанник отмечал, что во всех демократических государствах стало непреложной истиной, что экономическая политика должна осуществляться путем принятия таких управленческих решений, которые обусловлены нормами национальной конституции ${ }^{14}$.

Непосредственно Дж. Бьюкенен выделял три аналитических принципа в своей теории: методологический индивидуализм, концепция че-

${ }^{13}$ Норт Д. Институты, институциональные изменения и фрункционирование экономики. М., 1997. С. 34.

${ }^{14}$ См.: Совершенствование местного самоуправления сквозь призму конституционной экономики / под ред. А. Н. Костюкова. Омск, 2015. С. 64. 
ловека экономического (homo economicus) и рассмотрение политики как процесса обмена ${ }^{15}$. В краткой форме принцип методологического индивидуализма описывается им так: «Лишь индивиды осуществляют выбор и совершают действия. Коллективы как таковые не могут осуществлять ни выбора, ни действий, и анализ, исходящий из обратного, не соответствует канону научности» ${ }^{16}$.

В конфликтологическом аспекте наиболее интересен второй принцип теории конституционной экономики - концепция человека экономического. Как отмечает А. М. Сергеев, в экономической теории главной характеристикой homo economicus выступает рациональность, которая заключается в максимизации целевой функции при данных ограничениях. В указанном контексте рациональность понимается как предположение о том, что люди всегда стремятся в наибольшей степени увеличить уровень удовлетворения своих потребностей, добиваясь соотношения между выгодами и издержками ${ }^{17}$. При этом такая рациональность определяется каждым субъектом индивидуально. Многие экономисты поддерживают идею о том, что большинство людей стремится к удовлетворению своих эгоистичных интересов и желаний независимо от того, являются они сугубо материальными или нет ${ }^{18}$.

Модель человека экономического применяется в конституционной экономике расширительно, поскольку считается, что рациональное поведение присуще человеку не только в сфере экономики, но и в сфере политики, что для нас - конституционалистов - особенно важно, поскольку конституционное право - самое политическое из всех отраслей права ${ }^{19}$. Данная идея об инвариантности (симметрии) модели поведения человека для всех институтов основана на следующей логической фрормуле: «Если мы исходим из того, что на рынке индивид использует все возможности, которыми он располагает (в рамках действующих на рынке правил) в целях максимизации своего чистого благосостояния, то и мы, рассматривая соответствующую политическую среду, должны исходить из того, что индивид использует все возможности, которыми он располагает (в рамках политических правил) точно таким же образом» ${ }^{20}$. При этом сама политика представляет собой сложный взаимовыгодный обмен по правилам, установленным конституцией.

Однако если все индивиды будут вести себя рационально-эгоистически, это приведет к войне всех против всех. Что же заставит их прийти к

${ }^{15}$ См.: Бьюкенен Дж. Конституция экономической политики // Вопросы экономики. 1994. № 6. С. 104-113.

${ }^{16}$ Бьюкенен Дж. Конституционная экономическая теория. М., 2004. С. 172.

${ }^{17}$ См.: Сергеев $A$. M. Методологические основы и концептуальные положения конституционной экономики // Рос. юрид. журнал. 2014. № 3 (96). С. 13.

${ }^{18}$ См., подробнее: Карапетов А. Г. Экономический анализ права. М., 2016. С. 46 ; Мизес Л. фбон. Теория и история : интерпретация социально-экономической эволюции. Челябинск, 2009. С. 184-185.

${ }^{19}$ См.: Бреннан Дж., Бьюкенен Дж. Причина правил. Конституционная политическая экономия. СПб., 2005. С. 99.

${ }^{20}$ Там же. С. 99. 


\section{Вестник ВГУ. Серия: Право}

согласию в части выбора общего варианта поведения, что сдержит этого левиафрана? Важнейшим фрактором в достижении согласия по поводу выбора варианта поведения является неопределенность влияния возможных альтернатив на чистое благосостояние каждого участника взаимодействия. Дж. Бьюкенен объяснил это так: «Столкнувшись с реальной неопределенностью в отношении того, как повлияет действие какого-то конкретного конституционного правила на положение человека экономического, он, руководствуясь эгоистическим расчетом, сосредоточит свои усилия на выборе вариантов, которые устраняют или уменьшают возможность получения потенциально катастрофических вариантов» ${ }^{21}$. Иными словами, наличие фрактора неопределенности приводит к тому, что индивиды не в состоянии установить, окажутся они в долгосрочной перспективе выигравшими или проигравшими, в связи с чем в ситуации конституционного выбора они будут ориентироваться на такие правила, которые выгодны всем и каждому либо представляются им более «честными» $^{22}$. И такие «правила» получают закрепление в конституции как Основном законе государства.

Таким образом, ученый предложил свою трактовку общественного договора, дополнив ее постконституционным договором, устанавливающим правила, по которым государство должно действовать, занимаясь производством общественных благ; и если заключение конституционного договора теоретически не требует принуждения, поскольку выигрывают все от его заключения, то постконституционный договор (правила, которые нужно соблюдать при выборе варианта поведения в условиях неопределенности) должен содержать механизмы принуждения к соблюдению таких конституционных правил ${ }^{23}$. Подобным механизмом принуждения является конституционно-правовое принуждение, представляющее собой систему мер властного воздействия, оказываемого на субъектов конституционного права, с целью предупреждения или разрешения конституционных конфликтов. Ранее мы уже высказывали точку зрения, что конституционно-правовое принуждение является основным средством предупреждения и разрешения конфрликтов в государстве, что нашло свое дополнительное теоретическое обоснование и в приведенных работах по экономической теории.

Контуры области исследования конституционной экономики можно очертить следующими вопросами, сформулированными Дж. Бреннаном и Дж. Бьюкененом: «Что мы можем посоветовать самим себе в наших собственных обществах, располагая выгодами сотрудничества, с одной стороны, и перспективами возможных конфликтов - с другой? Какие правила «общественного порядка» заставляют нас оказывать неблагоприятное влияние друг на друга?» ${ }^{24}$.

\footnotetext{
${ }^{21}$ Бреннан Дж., Бьюкенен Дж. Указ. соч. С. 67.

${ }^{22}$ См.: Сергеев А. М. Указ. соч. С. 17.

${ }^{23}$ См.: Там же.

${ }^{24}$ См.: Бреннан Дж., Бьюкенен Дж. Указ. соч. С. 23.
} 
Из вышеизложенного можно сделать вывод, что индивиды принимают решения о вступлении в конституционный конфрликт, действуя при этом рационально (соотнося получаемое в результате конфрликта благо с затрачиваемыми издержками на его получение) в условиях ограничений, установленных в конституции в целях достижения некого общего блага, - тех правил политической игры, о которых «договорились» граждане государства в условиях неопределенности.

Чтобы продемонстрировать данный тезис, вернемся к нашему примеру с президентом. Выбирая вариант поведения при получении информации о ненадлежащем поведении губернатора, президент должен руководствоваться как минимум принципом правового государства и народовластия, с одной стороны, и принципом единства системы публичной власти - с другой, которые закреплены в соответствующих статьях Конституции РФ. Следовательно, выбор его варианта поведения для достижения субъективного блага (надлежащего осуществления публичной власти в регионе, имиджа публичной власти) должен быть подчинен конституционно значимым целям - установленным в государстве правилам политического обмена.

Приведенный экономический анализ юридически значимого поведения субъектов конституционного права в ситуации, которая может привести к конституционному конфликту, позволяет ответить на вопрос: каким должно быть поведение субъекта конституционного права в данном случае? Это поведение должно быть индивидуально-рациональным и ограниченным конституционными нормами. Проиллюстрируем это на нашем примере. Общественное благо, имеющее ценность для президента в данном примере, - доверие народа к власти и имидж этой власти, подорванный неэтичными действиями губернатора. Издержки, встречающиеся на пути к достижению президентом такого блага: отсутствие в законе такого основания для отрешения от должности; избрание губернатора населением региона и оказание, таким образом, ему поддержки со стороны значительной части граждан. Конституционные ограничения, влияющие на выбор варианта поведения: принципы народовластия, правового государства и федерализма. Выбор варианта поведения должен соответствовать данным ограничениям. Если же такие ограничения не принимаются во внимание и выбор варианта поведения осуществляется, исходя исключительно из цели достижения блага с любыми издержками, такая ситуация свидетельствует о нарушении постконституционного договора или, проще говоря, о неконституционности поведения.

Однако сегодня наука конституционного права не может позволить себе быть только теорией и должна иметь практическое выражение. В связи с чем в целях определения причин конституционных конфликтов в Российской Федерации, преследуемых их участниками интересов при выборе соответствующего варианта поведения, в 2021 г. нами был проведен опрос граждан Российской Федерации с использованием инструментов google-фрорм в информационно-телекоммуникационной сети «Интернет». 
По состоянию на 13 мая 2021 г. можно подвести промежуточные итоги ${ }^{25}$ данного опроса. В нем приняли участие 290 граждан Российской Федерации, проживающих на территории 28 субъектов РФ. Возраст респондентов составил: 18-25 лет (43\%); 24-45 лет (38,8 \%); 45-65 лет (17,2\%) и старше 65 лет (1\%). По виду основной деятельности респонденты распределились по следующим группам: студенты (43,3 \%); работники по найму $(28,9$ \%); государственные и муниципальные служащие (15,5 \%); самозанятые $(2,7 \%)$; пенсионеры $(2,7 \%)$; безработные $(1,4 \%)$ и иные группы $(5,5 \%)$.

На вопрос «Существуют ли конфликты в системе публичной власти?» $54,3 \%$ респондентов ответили положительно; $40,5 \%$ респондентов ответили, что конфликты существуют, но их сложно выявить ввиду закрытости системы публичной власти, и только $4,1 \%$ респондентов ответили, что конфликты в системе публичной власти в Российской Федерации отсутствуют. Данные показатели подтверждают известный тезис социологов о том, что конфликтность - обязательная и естественная характеристика общества, не преодолеваемая в государстве даже формированием единой системы публичной власти, где принцип единства ориентирует, казалось бы, на отсутствие внутренних противоречий.

Абсолютное большинство - 90 \% опрошенных - ответили, что конфликты существуют между органами публичной власти и гражданами, когда органы публичной власти нарушают или ограничивают права граждан.

В качестве основных возможных причин конституционных конфрликтов респонденты назвали следующие:

- различные интересы, преследуемые сторонами (63,9 \%);

- пробелы и коллизии законодательства (53,6 \%);

- несогласованность действий (50,5 \%);

- недостаточность финансового и ресурсного обеспечения $(38,1 \%)$.

Данные результаты свидетельствуют о том, что, по мнению опрошенных граждан, участники конституционных конфликтов все-таки стремятся достичь индивидуального блага вне зависимости от существующих конституционных ограничений (преследуют свои собственные интересы).

В ходе опроса респондентам также был задан вопрос о наиболее опти28 мальном способе разрешения конфликтов в системе публичной власти. Таковым способом респонденты признали:

- согласительные процедуры и переговоры (49,1\%);

- меры государственного принуждения (различные предписания, предупреждения о недопустимости нарушения, юридическая ответственность) $(35,7 \%)$;

- обращение в суд $(15,1 \%)$.

Данные результаты интересны тем, что респонденты посчитали судебную защиту самым «неподходящим» способом разрешения конституционных конфликтов, а самым оптимальным - не конституционно-правовое принуждение, а согласительные процедуры и переговоры.

${ }^{25}$ При написании настоящей статьи опрос еще не был завершен автором. 
Таким образом, поведение участников в ситуации, которая может привести к конституционному конфликту, может быть объяснено с позиций теории конституционной экономики (конституционной политической экономии). Такое поведение является индивидуально-рациональным и должно осуществляться в условиях существующих конституционных ограничений. В противном случае, когда индивид не учитывает конституционные ограничения при выборе варианта поведения, такое поведение не является экономически рациональным.

Применение в настоящей статье метода экономического анализа права к поведению участников конституционных конфликтов не претендует на вытеснение иных методов правового анализа и направлено на доказывание социальной, а не «текстуальной» природы конституционных конфрликтов, которые представляют собой правоотношение, социальное взаимодействие, заключенное в определенном поведении людей. И поскольку очевидно, что конституционные кондликты являются объективной реальностью, существующей в системе публичной власти в Российской Федерации, такое поведение и его природу необходимо изучать с позиций экономического и социологического подходов, что и было осуществлено в настоящей статье.

\section{Библиографический список}

Белкин А. А. Избранные работы 90-х годов по конституционному праву. СПб. : Юрид. центр Пресс, 2003. 319 с.

Бреннан Дж., Бьюкенен Дж. Причина правил. Конституционная политическая экономия. СПб., 2005. 272 с.

Бьюкенен Дж. Конституционная экономическая теория. М., 2004.

Бъюкенен Дж. Конституция экономической политики // Вопросы экономики. 1994. № 6. С. 104-113.

Гаджиев $\Gamma$. А. Российские исследования в области права и экономики : уточнение юридической картины мира. Выступление на IV Моск. юрид. форруме «Право и экономика : междисциплинарные подходы в науке и образовании» 6 апреля 2017 г. URL: http://www.ksrf.ru/ru/News/Documents/report_\% D0\%93\%D0\%B0\%D0\%B4\%D0\%B6\%D0\%B8\%D0\%B5\%D0\%B2_2017.pdf

Дюркгейл Э. О разделении общественного труда. Одесса, 1901.

Зимлиель Г. Sociologie. Leipzig, 1908.

Kapaneтов A. Г. Экономический анализ права. М. : Статут, 2016. 528 с.

Керилов Д. А. Методология права. М., 2009. 520 с.

Конституционная экономика / отв. ред. Г. А. Гаджиев. М. : Юстицинформ, 2010. 256 c.

Конституционная экономика : учеб. для юрид. и экон. вузов / П. Д. Баренбойм [и др.]. М., 2006. 528 с.

Кудрявиев B. H. Избранные труды по социальным наукам : в 3 т. М. : Наука, 2002. Т. 2. 282 с.

Мизес Л. фбон. Теория и история : интерпретация социально-экономической эволюции. Челябинск, 2009. 366 с.

Hорт Д. Институты, институциональные изменения и функционирование экономики. М., 1997. 180 с. 
Очерки конституционной экономики. 23 октября 2009 года / под ред. Г. А. Гаджиева. М. : Юстицинформ, 2009. 279 с.

Сергеев A. M. Методологические основы и концептуальные положения конституционной экономики // Рос. юрид. журнал. 2014. № 3 (96). С. 7-22.

Совершенствование местного самоуправления сквозь призму конституционной экономики / под ред. А. Н. Костюкова. Омск : Изд-во Омского ун-та им. Ф. М. Достоевского, 2015. 253 с.

Сорокин П. А. Преступление и кара, подвиг и награда : социологический этюд об основных формах общественного поведения и морали. М. : Астрель, 2006. $624 \mathrm{c}$.

Третьяк И. А. Конституционная конфликтология. М. : Проспект, 2021. 208 c.

Третьяк И. А. Конституционно-конфрликтная диагностика. Омск : Изд-во Омского ун-та, 2021. 122 с.

Юридическая конфрликтология / под ред. В. Н. Кудрявцева. М. : Изд-во PAH, 1995. 316 c.

\section{References}

Belkin A. A. Selected works of the 90s on constitutional law. St. Petersburg. Publishing house «Law Center Press». 2003. 319 p. (In Russ).

Brennan J., Buchanan J. The reason for the rules. Constitutional Political Economy, St. Petersburg, 2005, 272 p. (In Russ).

Buchanan J. Constitutional economic theory. Moscow, 2004. (In Russ).

Buchanan J. The Constitution of Economic Policy // Economic issues. 1994. № 6. P. 104-113. (In Russ).

Gadzhiev G. A. Russian studies in the field of law and economics: clarification of the legal picture of the world. Speech at the IV Moscow Legal Forum «Law and Economics: Interdisciplinary Approaches in Science and Education» on April 6, 2017. http://www.ksrf.ru/ru/News/Documents/report_\%D0\%93\%D0\% B0\%D0\%B4\%D0\%B6\%D0\%B8\%D0\%B5\%D0\%B2_2017.pdf. (In Russ).

Durkheim E. On the division of social labor. Odessa. 1901. (In Russ).

Simmel G. Sociologie. Leipzig. 1908. (In Russ). Russ).

Karapetov A. G. Economic analysis of law. Moscow. Statute. 2016. 528 p. (In

Kerimov D. A. Methodology of law. Moscow, 2009. 520 p. (In Russ).

30 Constitutional economy. / Ed. by G. A. Gadzhiev. M. Justicinform. 2010. 256 p. (In Russ).

Constitutional economy : textbook / P. D. Barenboim [et al.]. Moscow, 2006. 528 p. (In Russ).

Kudryautsev V. N. Selected works on social sciences. Moscow. Nauka. 2002. Vol. 2. 282 p. (In Russ).

Mises L. von. Theory and history: an interpretation of socio-economic evolution. Chelyabinsk. 2009. 366 p. (In Russ).

North $D$. Institutes, institutional changes and functioning of the economy. Moscow, 1997. 180 p. (In Russ).

Essays on constitutional economics. October 23, 2009 / edited by G. A. Gadzhiev. Moscow. Justicinform, 2009. 279 p. (In Russ). 
Государственная власть. Законодательный процесс...

Sergeev A. M. Methodological foundations and conceptual provisions of the constitutional economy // Russian Law Journal. Scientific and theoretical: № 3 (96) / 2014. p. 7-22. (In Russ).

Improving local self-government through the prism of the constitutional economy: a collective monograph / Edited by A.N. Kostyukov. Omsk. Publishing house of the Omsk State University named after F.M. Dostoevsky. 2015. 253 p. (In Russ).

Sorokin P. A. Crime and punishment, feat and reward: a sociological study on the main forms of social behavior and morality. Moscow. Astrel, 2006. 624 p. (In Russ).

Tretyak I. A. Constitutional conflictology. Moscow, Prospect. 2021. 208 p. (In Russ).

Tretyak I. A. Constitutional-conflict diagnostics. Omsk. Publishing house of the Omsk University. 2021. 122 p. (In Russ).

The juridical conflictology. Moscow. 1995. 316 p. (In Russ).

Олский государственный университет илени Ф. М. Достоевского

Третьяк И. А., кандидат юридических наук, доцент кафбедры государственного и мунииипального права

E-mail: irina.delo@yandex.ru
Dostoevsky Omsk State University

Tretyak I. A., Candidate of Legal Sciences, Associate Professor of the State and Municipal Law Department

E-mail: irina.delo@yandex.ru 